\title{
Research on Construction Dimensions of College English Learning Cloud Space Based on TPACK Framework Design
}

\author{
Yan Hu \\ Shandong Vocational College of Light Industry, Zibo, Shandong 255300, China
}

Keywords: TPACK framework, Learning cloud space, Teaching application

\begin{abstract}
As a new type of subject knowledge framework that conforms to the trend of contemporary informatization education, TPACK, which integrates technology, is increasingly being researched and promoted by the education community. Based on the analysis of the content of TPACK framework and the composition of instructional design patterns, this paper expounds the enlightenment of TPACK framework to instructional design, constructs the construction dimension of college English learning cloud space based on TPACK framework, and combines teaching needs with learning cloud space characteristics. The system architecture is constructed. Secondly, the application strategy of learning cloud space in college English teaching is expounded. Combined with learning cloud space, its application mode in college English teaching is introduced: flipped classroom mode. The research results show that the customized learning cloud space and its application can improve the efficiency of college English teaching and promote students' mastery of English application skills.
\end{abstract}

\section{Introduction}

TPACK, known as the subject-mapping knowledge of integrated technology, represents a new teacher knowledge framework in the information technology era and is essential for facilitating the integration of curriculum and professional teaching knowledge. In 2005, American scholars Koehler and Mishra first proposed the Technical Pedagogical and Content Knowle dge for integration technology. Since TPCK was not easy to read, it was renamed TPACK. There are seven elements in the TPACK knowledge framework. Among them, technical knowledge (TK), pedagogical knowledge (PK), subject content knowledge (CK) are three single elements; subject teaching method knowledge (PCK), integrated technology teaching method knowledge (TPK), integrated technology subject content Knowledge (TCK) and integrated technology discipline knowledge (TPCK) are four composite elements that are intertwined by three single elements.[1] Among them, TPCK is a combination of technology and subject knowledge and pedagogical knowledge. It has a core dominance for the use of technically effective teaching by subject teachers. The interaction between the three knowledge elements is shown in Figure 1.

(1) CK-Subject content knowledge refers to the subject knowledge that is actually learned or taught by students. It includes two dimensions: C1K-discipline content (specific subject syllabus, knowledge of curriculum standards), C2K-discipline content knowledge (knowledge, concepts, methods, relationships, etc. of specific disciplines and knowledge of the relationship between specific disciplines and other disciplines) ). This type of knowledge is highly specialized, different in disciplines, different in level, and covers a wide range of content. Therefore, it is especially important for instructors in specific disciplines to have a deep understanding of the basic knowledge of their subjects.[2]

(2) PK-pedagogy knowledge is a common type of knowledge, including two dimensions: P1K-knowledge of student learning processes (mainly including developmental psychology and educational psychology) and P2K-supporting methods and strategies . This knowledge is reflected in the teaching links such as curriculum design, classroom management, and teaching evaluation. Mastering pedagogical knowledge requires teachers to have a deep understanding of the student's learning process, that is, to understand the process of students' acquisition of knowledge, mastery of skills and ability improvement. On this basis, teachers can better understand the teaching process 
and thus rationally apply strategies and Methodological knowledge to design and conduct teaching activities.

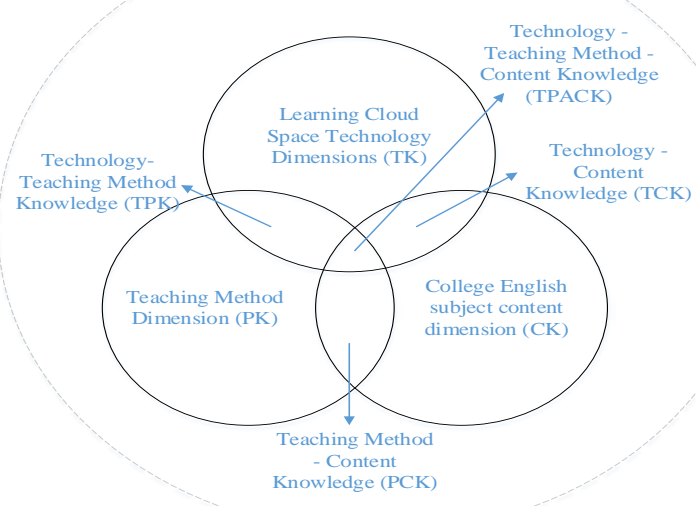

Figure 1. Construction Dimensions of College English Learning Cloud Space Based on TPACK

(3) TK-technical knowledge, the technology here refers to the "educational technology" applied to education, including traditional technology and digital technology. Technical knowledge includes three dimensions: T1K-availability and restrictive understanding of specific technical teaching functions, T2K-knowledge of teaching tooling methods, and T3K-knowledge of methods for learning new technologies. Over time, most traditional educational techniques have become very common, achieving perceptual transparency and teachers being able to use them skillfully. However, relatively speaking, digital technology is ever-changing and frequently updated. Therefore, we must avoid falling into "functional fixation".[2] We need to constantly update our technical knowledge, look at the availability and limitations of technology from a development perspective, and learn to be smooth. Use technology to solve teaching problems.

The knowledge of subject teaching in TPACK - integration technology refers to the knowledge of using a variety of supportive information technologies to teach content in a subject. The essence is the understanding of the interaction between CK, PK and TK. Every "inferiority problem" faced by teachers is the unique integration of these three elements. Different teachers and teachings have different teaching plans. Teachers need to have a high degree of cognitive fluency and flexibility in each of the fields of CK, PK, and TK. It is also necessary to develop this flexibility in their intersections to achieve a high sensitivity to specific teaching contexts. In order to design a better teaching integration program.[3]

\section{Cloud Space and its Advantages in College English Teaching}

\subsection{Overview of cloud space}

The cloud is the place to gather information. The cloud computing is a mechanism for processing, storing and sharing data. The teaching cloud space provides system space for the integration of teaching resources, the concentration of services and the sharing of applications. With an open information service platform, cloud space can provide the required services in a timely manner, such as the storage of course resources, the aggregation of content, the sharing of information, and the communication of messages. Cloud space is characterized by providing course learning and storing course materials in the cloud.[2]It strengthens the communication between teachers and students through the creation of a language learning community composed of teachers and students. Communication, the students' self-creation of the curriculum and the prejudice to the completion of the study will be liberalized, and at the same time, the establishment of resource expansion platforms such as enterprises, schools, publishing houses and social groups will be realized. At the same time, it integrates functions such as live video broadcast and sharing, network learning and electronic classrooms to design the college English cloud curriculum. The staff provides a platform 
for comprehensive display and real-time interaction. With this platform, teachers and students can upload teaching and learning content only by real-name registration, and at the same time, conduct after-school testing and teaching management. Teaching and learning English in a real-life language environment and a powerful real-name learning space.

\subsection{Learning cloud space application service advantages}

Cloud computing technology has a very secure and reliable data storage system and a convenient and fast network service system. Learning cloud space uses cloud computing technology to store application services in the cloud, making full use of the powerful computing power of the data center, effectively extracting, organizing, classifying and indexing application services, and effectively sharing various application services (including tools). Thereby achieving the adaptability of the application service in the learning system. Cloud Space concentrates all available application services (including tools) on a cloud platform. Under the unified management and deployment of the platform, it provides users with various learning function services required for English learning from all aspects of listening, speaking, reading and writing. The rules of dynamically scheduling application services in cloud computing in the market mechanism to survive the fittest The quality is improved, and the personalized configuration of the service is conducive to the convenience of functional services.[3]

\subsection{Based on cloud space, the advantages of college English teaching mode}

A wealth of teaching resources for the creation of real language situations. Cloud space provides a new concept and the development of college English teaching. Compared with traditional English teaching, the real language environment and rich teaching resources in the cloud space can greatly increase the technical content of college English teaching, and improve the overall quality of students while cultivating their language skills. Based on the single disadvantage of teaching content, the traditional English classroom teaching model is easy to cause students' fatigue and boredom. By introducing cloud space, teachers can focus on audio, video, text, animation and other teaching media while teaching, and promote the effective development of teaching work with the creation of an active and interesting language environment. By taking advantage of the cloud space, students can free themselves from the constraints of time and space. Cloud space provides teachers with rich and personalized services that add to the teaching and learning process, while an open language learning environment helps students use a variety of information resources to conduct autonomous learning. Based on their own English proficiency and personality characteristics, students can select learning content, define learning tasks, formulate learning plans, design evaluation indicators, and speak freely on the platform.

\section{The Construction Dimension and System Architecture of College English Learning Cloud Space}

\subsection{Construction of cloud space for college English learning based on TPACK}

In order to effectively implement the three-dimensional thinking of college students' English learning cloud space construction, this study relies on the spatial customization of cloud space to design the system architecture of college English learning cloud space.The space support layer is connected downwards to the cloud infrastructure to provide spatial basic services for spatial core functions, including personalized spatial dynamic configuration, learning resource organization and management, learning process visualization management, spatial interaction and information flow, and learning data records. Support with environments such as storage. Obviously, the former mainly completed the learning cloud space infrastructure of the technical dimension through inheritance, while the latter partially realized the organization and management of the content dimension of the college English subject.[4]

\subsection{The application mode of cloud space in college English teaching}

According to the teaching characteristics of different teaching contents in college English 
teaching, the learning cloud space also has a corresponding application mode. For example, the teaching of regular English language knowledge can adopt the teaching mode of flipping classroom, the theme of cultural learning can adopt the subject inquiry teaching mode, and the skills training such as writing, reading and translation can be carried out by mixed teaching mode. This study takes the three modes of college English flipping, subject inquiry learning and mixed learning supported by cloud space as an example to illustrate the application of learning cloud space in college English teaching. The flip classroom teaching mode supported by the learning cloud space is shown in Figure 2.

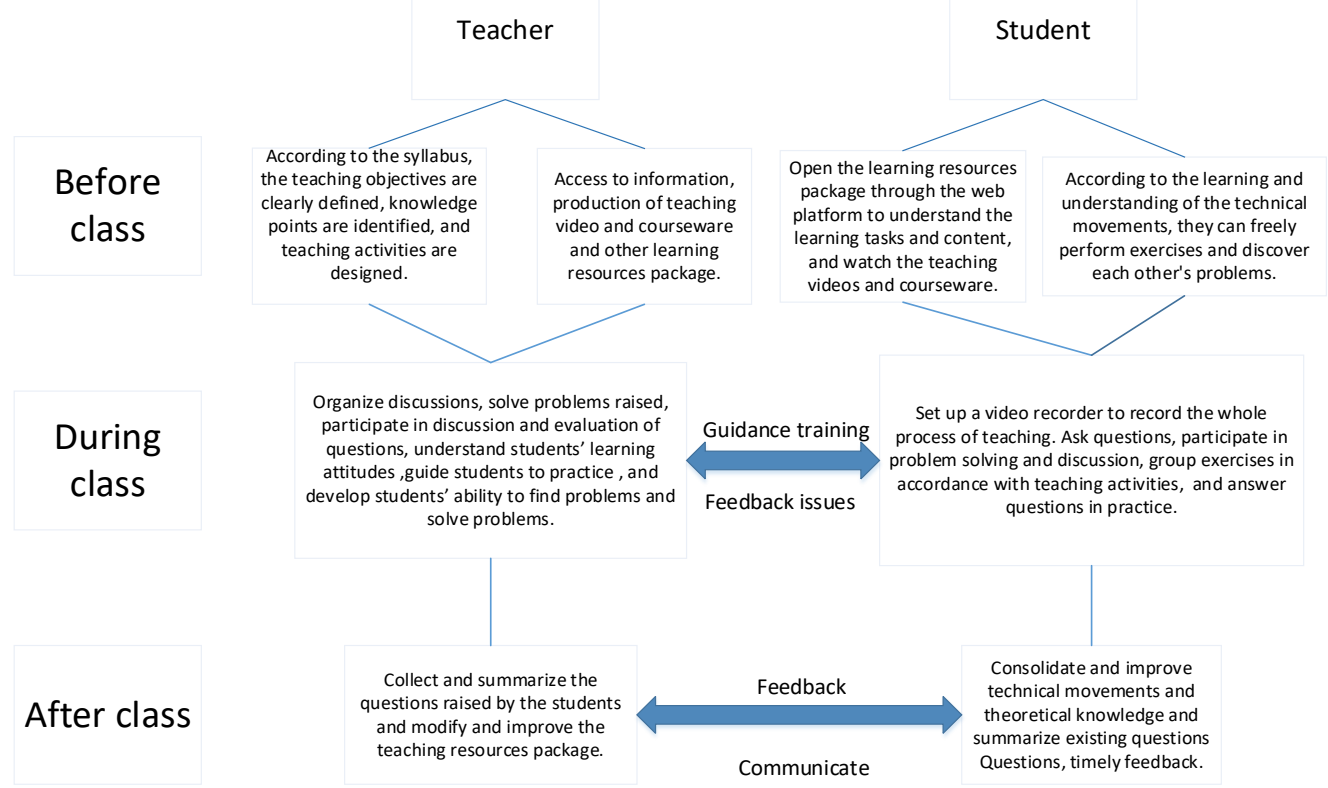

Figure 2. The structural diagram of flip classroom teaching mode

Before the class, the teacher recorded the language learning knowledge points into the micro-course video, and the corresponding courseware, exercises and other resources were provided to the learners through the learning cloud space. At the same time, teachers design learning activities based on learning cloud space, students participate in online learning activities, exercise exercises and summarize learning gains and confusion to prepare for the offline classroom. Teachers provide tutoring to students' online learning activities, and design classroom activities in combination with students' pre-class learning. In the classroom, teachers make breakthroughs in language knowledge points according to the pre-class students' learning situation, and analyze and discuss students' learning confusion and problems. Communicate, organize students to carry out skills training such as listening, speaking, reading and writing, and guide students to conduct independent inquiry and collaborative learning. Through the teaching activities such as skills training, communication and reporting, problem solving and self-assessment and mutual evaluation, students will internalize the teaching content of language knowledge, listening, speaking, reading and writing skills. [4]After class, teachers will provide solid learning based on students' classroom performance. Materials, investigate learning effects and improve instructional design, and summarize the teaching. Students use the consolidation materials provided by teachers to consolidate learning, check for missing, and summarize and feedback evaluation.

\section{Analysis of Application Effects}

In order to test whether the English learning solution based on learning cloud space effectively promotes the English learning effects of students listening, speaking, reading, writing and translating, we have evaluated and compared the learning effects of group A and group B students. . After the end of the experiment, the students in the experimental group and the control group were evaluated for learning effects, and the average scores of the two groups of students evaluated in five 
aspects were calculated, and the data was converted into a rectangular chart, as shown in Figure 3.

96 people in the martial arts class were divided into the control class and the experimental class of 48. The experimental class followed the flipped classroom for teaching. The control class was conducted according to the traditional teaching mode. It took 2 class hours per week for 10 weeks for a total of 20 class hours; Teachers conducted questionnaire surveys and interviews, used Excle 2007 and SAS to conduct statistical analysis on pre-processed data, and finally conducted comparative analysis of teaching effects through assessment evaluation.

Table 1 Theoretical knowledge, technical assessment and achievement test scores of the control class and experimental class after the teaching experiment.

\begin{tabular}{|l|l|l|l|l|}
\hline Factor & $\begin{array}{l}\text { Control class } \\
(\mathrm{x} 1)\end{array}$ & $\begin{array}{l}\text { Experimental class } \\
(\mathrm{x} 2)\end{array}$ & $\mathrm{t}$ & P-Value \\
\hline Theoretical knowledge & 26.55 & 32.95 & -6.082 & $<0.0001$ \\
\hline Technical assessment & 20.00 & 24.95 & -6.349 & $<0.0001$ \\
\hline Achievements & 19.93 & 21.79 & -4.597 & $<0.0001$ \\
\hline $\begin{array}{l}\text { Comprehensive } \\
\text { assessment }\end{array}$ & 78.30 & 83.35 & -4.949 & $<0.0001$ \\
\hline
\end{tabular}

\section{Comparision of control class and experimental} class after the teaching experiment.

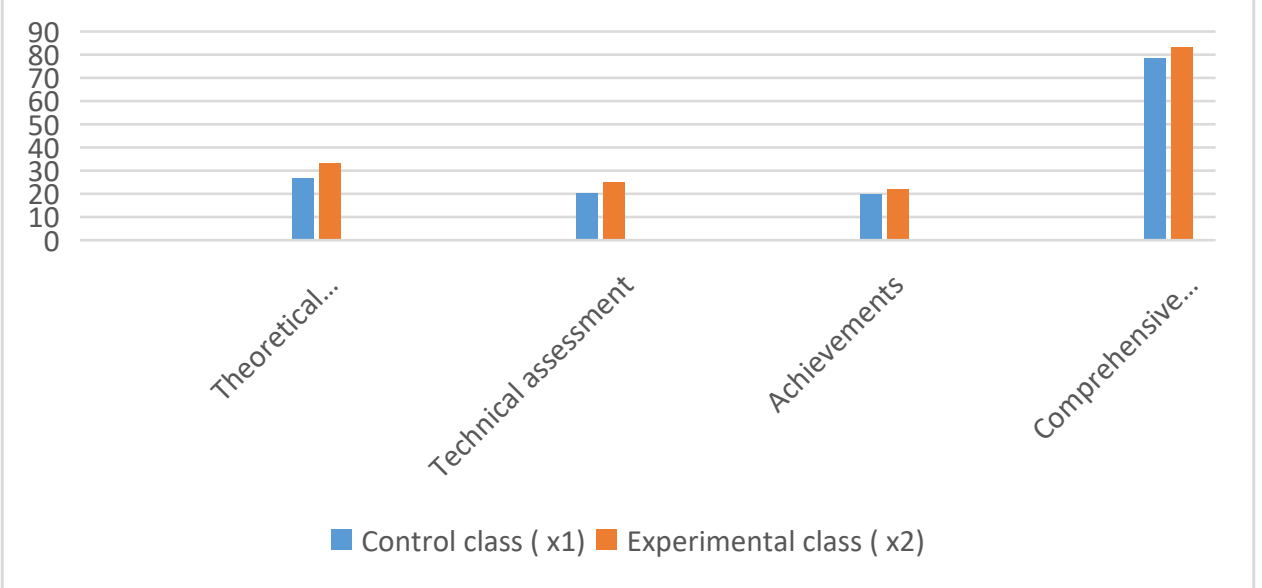

Figure. 3 Comparision of control class and experimental class after the teaching experiment.

In summary, the customized college English learning cloud space and its teaching solutions can not only help teachers improve teaching efficiency, but also promote students to improve listening, speaking, reading, writing, and relying on the convenience of virtual space. English learning effects in translation and other aspects.

\section{Conclusion}

Based on TPACK framework for college English The learning cloud space construction dimension under the teaching application scenario is analyzed. The system architecture of learning cloud space is constructed from the cloud platform infrastructure layer, space support layer, core function layer and application interaction layer. Flip classroom in learning cloud space application and college English teaching is introduced and the practical results show that the college English teaching scheme based on learning cloud space in this study helps to promote the learning effects of listening, speaking, reading, writing and translating. In the future, we intend to further refine the application effect verification and analysis, improve the cloud space and its application theory construction; at the same time, based on data science, explore the theory and application of spatial adaptation of the whole process. 


\section{References}

[1] GigaSpaces. Dimensions - Cloud Computing and Its Applications 2008[J]. Computer Networks, 2014, 68(5):1+4.

[2] Zhan Q, Yu L. Segmentation of LiDAR Point Cloud Based on Similarity Measures in Multi-dimension Euclidean Space[J]. 2012,14(1):349+357.

[3] Xue L X, Wang Z C, Yong-Shu L I. Study on edge detection of multi-spectrum remote sensing image based on multi-dimension cloud space[J]. Science of Surveying \& Mapping, 2008, 33(1):186+187.

[4] Zhan Q, Yu L. Segmentation of LiDAR Point Cloud Based on Similarity Measures in Multi-dimension Euclidean Space[M]// Advances in Computer Science and Engineering. Springer Berlin Heidelberg, 2012(3):349+357. 